\section{Prevalence and experience of harassment of people with mental health problems living} in the community

\author{
KATHRYN M. BERZINS, ALISON PETCH and JACQUELINE M. ATKINSON
}

\begin{abstract}
Background The levels and experiences of harassment of people with mental health problems in the community compared with those of the general population have not been explored.
\end{abstract}

\begin{abstract}
Aims To measure the levels and experience of harassment experienced by people with mental health problems in the community in Scotland and compare them with the general population.
\end{abstract}

\begin{abstract}
Method Experiences of harassment were collected by interviewing 165 individuals with mental health problems and a control group of 165 people from the general population.
\end{abstract}

Results Harassment in the community was found to be twice as common for individuals with mental health problems (4I\%) than for those in the general population (15\%). The harassment commonly involved verbal abuse referring to the individual's mental health problems and was committed primarily by teenagers and neighbours.

\section{Conclusions Harassment has a} significantly higher prevalence among individuals with mental health problems living in the community and is believed to have a detrimental effect on mental health.

\footnotetext{
Declaration of interest This study was funded by the Communities Fund and was the result of a partnership between the Nuffield Centre for Community Care Studies, University of Glasgow, the National Schizophrenia Fellowship (Scotland) and the Scottish users' network.
}

Stigma and discrimination have long been problems for people with mental health problems living in the community, and are currently the focus of campaigns by, among others, the Royal College of Psychiatrists (2001) and the Department of Health (2001). This research was prompted by concerns from mental health organisations hearing anecdotal accounts of individuals experiencing harassment in their communities. No previous research explored the prevalence of such harassment, particularly in comparison with the general population and across different communities. Only one study, carried out for MIND, had examined harassment previously, finding that $50 \%$ of its respondents had experienced harassment in the workplace and community (Read \& Baker, 1996). The study was limited, however, by its use of a self-selecting sample. Kelly \& McKenna (1997) found that $60 \%$ of their sample (in a quality-of-life study) experienced harassment, the majority living in local authority 'difficult to let' areas.

\section{METHOD}

\section{Definition of harassment}

There is no single definition of harassment: it can take a variety of forms, both verbal and physical, and have a variety of motives. It can be conducted by one person or a group of people, against one person or several. The impact of a specific behaviour will be different depending on the individual who experiences it; additionally, perpetrators of harassment may not see their behaviour as causing distress to others.

For the purposes of this research, harassment was defined as:

(a) a person carrying out an action that may reasonably result in another feeling harassed;

(b) the act need not necessarily be repeated;

(c) the perpetrator need not necessarily have acted with intent.
For the purposes of the study, communitybased harassment embraced harassment both within and outside of the home, but excluded workplace harassment, childhood abuse and domestic abuse.

The Multi Centre Research Ethics Committee for Scotland and the appropriate local research ethics committees granted ethical approval for the study.

\section{Sample}

Study areas

The four types of area that were sampled were those typical in Scotland:

(a) cities (Aberdeen, Glasgow and Dundee);

(b) towns (East Kilbride, Hamilton, Falkirk and Cumbernauld);

(c) peripheral housing estates (Drumchapel and Castlemilk, both peripheral to Glasgow);

(d) scattered rural settlements (Dumfries and Galloway).

Each site was served by one or more community mental health teams through which the sample was accessed. It was not the intention to make systematic comparisons between the different localities.

A total of 165 individuals with mental health problems and 165 individuals in the general population were interviewed. Each sample comprised interviews with 40 people from each of cities, towns and rural settlements and 45 from peripheral housing estates.

\section{Inclusion criteria}

The individuals with mental health problems were experiencing severe and enduring mental health problems as defined by the Scottish Framework for Mental Health Services (Scottish Executive, 1997). The assumption was that the mental health problems of these individuals would have had more impact on their lives than those of individuals who had experienced a single episode or problems of a more transient nature. The age range was between 25 and 65 years.

\section{Exclusion criteria}

People with dementia were excluded as being a distinct group with particular needs. Homeless people also were excluded from the sample. It was considered that the nature of this population, including high incidences of mental health problems, 
would lead to difficulties in providing a matched sample. In the general population, those who had been in contact with mental health services within the past 10 years were excluded.

\section{Research instruments}

A face-to-face interview was chosen to provide a safe environment within which the complex issues of harassment could be explored. The interview was structured in format but allowed less structured responses when taking descriptions of any incidents of harassment. The interview schedule was developed after a series of focus groups involving people using mental health services in both the voluntary and statutory sectors. The same interview was administered to both sample groups.

The interview provided sociodemographic information. Interviewees were asked if they felt that they had experienced harassment and, if so, they were asked to describe their experiences. The interviewers recorded the experiences, using prompts to ensure that information was gathered about what the harassment consisted of, where it had taken place, who was committing it, why it was felt to be occurring and the impact it had on the interviewee.

\section{Procedure}

Each community mental health team was approached and asked to access a sample of its users. Service users meeting the inclusion criteria were approached by their community psychiatric nurse and asked if they would be prepared to be interviewed. If consent was given, they received an information sheet and their details were passed to the researcher. The researcher then contacted them to arrange the interview. All participants were interviewed in their own homes or at their resource centre. The general population was assessed by interviewers calling at their homes and matching them on gender, age and type of housing.

The data were collected between June 2000 and March 2001. A team of eight specifically trained interviewers carried out the interviews.

\section{Analysis}

The quantitative data were analysed using MINITAB, Version 12 for Windows. Comparisons between subgroups were made using the $\chi^{2}$ test. The qualitative data were analysed using QSR NUD*IST.

\section{RESULTS}

A total of 330 people were interviewed: 165 people with mental health problems and 165 people in the general population.

\section{Socio-demographic characteristics}

Table 1 reports the socio-demographic characteristics of the two samples, including gender, age and employment status. If they were unemployed, they were asked how often they went out of the home. The table gives information about the type of property the participants lived in, whether they lived alone and the length of time they had lived in both their property and the area.

There was a significant difference between the numbers of people in employment in the two groups: $53 \%(n=88 / 165)$ of the general population were employed or were students compared with $5 \%(n=9 / 165)$ of people with mental health problems. All those with mental health problems $(n=6)$ and $35 \%(n=29 / 84)$ of those in the general population who were employed worked part-time. Those who were unemployed $(n=233 / 330)$ were asked how often they went out of their homes. Eighty per cent or more of both samples said that they went out either on a daily basis or several times each week. Forty-five per cent $(n=45)$ of the people with mental health problems lived alone, which was $30 \%$ more than in the general population $(n=25)$.

The ownership of property differed between the groups: $21 \%(n=93)$ more people with mental health problems lived in local-authority-owned accommodation than in the general population $(n=60)$. Over $70 \%$ of both samples (sample with mental health problems, $n=121 / 165$; general population sample, $n=117 / 165$ ) had lived in their area for over 20 years.

\section{Levels of harassment}

Table 2 shows the overall reporting of harassment and where the harassment occurred. Sixty per cent (99/165) of people with mental health problems and $44 \%$ $(73 / 165)$ of the general population reported experiencing some form of harassment $\left(\chi^{2}=8.21, P=0.004\right)$. Figures for incidences of harassment in the workplace and bullying while at school are detailed in Table 2 but are not included in the full analysis. There was a significant difference in the overall levels of harassment between the individuals with mental health problems and the general population. There was a significant difference in the location of the harassment, with $41 \%(67 / 165)$ of people with mental health problems experiencing harassment in the community compared with $15 \%(24 / 165)$ of the general population $\left(\chi^{2}=20.42, P<0.001\right)$. People from the general population were more likely to have experienced harassment in the workplace, reflecting the higher number of this sample in employment $\left(\chi^{2}=13.33\right.$, $P<0.001$ ).

The results reported below refer only to the harassment experienced in a community setting.

\section{Socio-demographic characteristics and harassment}

There were three socio-demographic variables showing significance. As can be seen in Table 3, age showed a significant influence on whether a person with mental health problems had experienced harassment, although this was not the case in the general population $\left(\chi^{2}=8.77\right.$, $P=0.033)$. When the two samples were combined an influence was shown but, because it was a weak level, it was not thought to be reliable $\left(\chi^{2}=8.40\right.$, $P=0.038)$. A significant association between people living in local authority accommodation and the prevalence of harassment was evidenced within the general population sample and when both samples were tested.

The type of area in which people lived did not influence whether they were likely to experience harassment or not. The prevalence of harassment between the two samples differed to the same extent across all areas (between $27 \%$ and $30 \%$ ), except in the cities, where it was $17 \%$. People living on their own were not significantly more likely to have experienced harassment, although there was a higher prevalence across both samples. A lower (but not significant) number had experienced harassment while living in supported accommodation compared with those people living in mainstream accommodation.

\section{Features of harassment}

Table 4 shows that in both samples verbal abuse was the most common form of harassment. There was one feature specific 
Table I Socio-demographic characteristics of participants ( $n, \%)$

People with mental health General population problems $(n=165)$ $(n=165)$

\begin{tabular}{|c|}
\hline \multirow{2}{*}{ Gender } \\
\hline \\
\hline Female \\
\hline Age (year \\
\hline $25-34$ \\
\hline $35-44$ \\
\hline $45-54$ \\
\hline $55-6$ \\
\hline
\end{tabular}

Employment status

Employed/student

Unemployed

Living circumstances

Lives alone

Lives with family/friend

Frequency of leaving the home

Daily

Several times per week

Weekly/monthly

Type of area

City

Town

Rural area

Peripheral estate

Type of property

Ground-floor flat

First or higher floor

Terraced house

Semi-detached house

Detached house/other

Owner of property

Local authority

Housing association

Privately owned

Privately rented/other

Supported accommodation

Yes

No

Time in property (years)

$<2$

2-5

6-10

II-20

$>20$

Time in area (years)

$<5$

6-10

II-20

$>20$
71 (43)

94 (57)

71 (43)

94 (57)

27 (16)

27 (16)

47 (28)

47 (28)

48 (29)

$48(29)$

$43(27)$

$43(27)$

9 (5)

$88(53)$

$156(95)$

77 (47)

74 (45)

25 (15)

91 (55)

140 (85)

72 (46)

37 (48)

54 (35)

27 (35)

30 (19)

$13(17)$

40 (24)

40 (24)

40 (24)

40 (24)

40 (24)

40 (24)

45 (28)

45 (28)

20 (12)

20 (12)

69 (42)

44 (27)

32 (19)

48 (29)

26 (16)

35 (2I)

18 (II)

18 (II)

93 (57)

$60(36)$

30 (18)

15 (9)

$36(22)$

75 (45)

$6(3)$

$15(10)$

24 (15)

NA

I4I (85)

NA

29 (18)

24 (15)

50 (30)

31 (19)

33 (20)

40 (24)

27 (16)

37 (22)

26 (16)

33 (20)

$15(9)$

14 (9)

$13(8)$

$17(10)$

17 (10)

$17(10)$

12I (72)

II7 (7I)

NA, not applicable.

to the people with mental health problems that over half of the sample described: having those problems exposed. This happened most commonly alongside verbal abuse. People frequently spoke of being called derogatory names:

$\therefore$. they waited for me and followed me again, they were calling me names such as "loony" and saying "you should be locked up".' (Woman, 2534 years, Dundee)

Unwanted interference frequently was reported, taking various forms including false accusations to the authorities or nuisance telephone calls.

'I started getting telephone calls about two and a half years ago. Groups of kids and young people were making calls to my house. They had found out I was on my own and I was fair game.' (Man, 45-54 years, Aberdeen)

The general population also described similar incidents:

'On Friday night, two days ago, our window was broken by a gang of teenagers who are targeting us.' (Man [general population] 35-44 years, Cumbernauld)

Other features of harassment that interviewees described included being physically threatened and, on occasion, actually assaulted.

\section{Who was committing the harassment}

Teenagers and neighbours were the two groups most frequently mentioned as committing the harassment across both samples and all types of area. The teenagers committing the harassment were often in groups of two or more:

'It was mainly young people about the streets aged about 14 or 15.' (Man, 44-55 years, Drumchapel)

The harassment from teenagers predominantly consisted of verbal abuse; they were largely thought to commit harassment as a result of influence from either their parents or peers. Teenagers' ignorance of mental health problems also was given as a reason for their behaviour.

The general population also described harassment from teenagers:

they hang around in my close [communal staircase] drinking and using abusive language at all hours and throwing stones at my windows.' (Woman [general population], 25-34 years, Castlemilk)

Neighbours also primarily committed verbal abuse: 
Table 2 Overall reporting of harassment by setting $(n, \%)$

\begin{tabular}{|c|c|c|c|}
\hline & $\begin{array}{l}\text { People with mental } \\
\text { health problems } \\
(n=165)\end{array}$ & $\begin{array}{l}\text { General population } \\
\qquad(n=165)\end{array}$ & Statistics \\
\hline Overall reporting of harassment & $99(60)$ & $73(44)$ & $\begin{array}{c}P=0.004 \\
\chi^{2}=8.21 \\
\text { d.f. }=I\end{array}$ \\
\hline Type of harassment & & & \\
\hline Community & $67(4 I)$ & $24(15)$ & $\begin{array}{c}P<0.00 I \\
\chi^{2}=20.42 \\
\text { d.f. }=\text { I }\end{array}$ \\
\hline Workplace' & $16(10)$ & $30(18)$ & $\begin{array}{c}P<0.001 \\
\chi^{2}=13.33 \\
\text { d.f. }=1\end{array}$ \\
\hline Other & $9(5)$ & $9(5)$ & $\begin{array}{c}P=0.493 \\
\chi^{2}=0.47 \\
\text { d.f. }=I \\
\text { NS }\end{array}$ \\
\hline Bullying while at school & $7(4)$ & $10(6)$ & $\begin{array}{c}P=0.150 \\
\chi^{2}=2.07 \\
\text { d.f. }=I \\
\text { NS }\end{array}$ \\
\hline
\end{tabular}

I. More participants reported experiencing harassment in the workplace than were in employment at the time of interview because since then they had stopped working.

'Two neighbours, one I had helped in the past, laughed at me and made "mental" signs at me.' (Woman, 55-65 years, Drumchapel)

The finding that $21 \%$ of the interviewees with mental health problems had experienced harassment coming from within their families was unexpected; nobody from the general population spoke of harassment coming from within their family:

'My brother-in-law used to harass me for my sleeping tablets.' (Man, 35-44 years, East Kilbride)
This harassment was not as a result of 'overanxious' carers reminding people to take medication: it was of a specifically malicious nature. People described being taken advantage of for their welfare benefits or medication, the relative knowing that they felt unable to stand up for themselves. They also felt that their mental health problems were often referred to, with family members calling them names and making derogatory references to their mental health:

\begin{abstract}
'It sounds stupid but I had ECT [electroconvulsive therapy] treatment for my depression and members of my family, especially my sister, thinks it's funny. She calls me "sparky". I find it very hurtful and l've tried to talk to them but she keeps on about it.' (Man, 55-65 years, Dundee)
\end{abstract}

\section{Why people felt that they were experiencing harassment}

There were substantial differences between the samples in the reasons why people felt that they were experiencing harassment. When the people with mental health problems knew the person committing the harassment, the majority felt that it was happening because they were known to have mental health problems:

'They do it because they don't understand mental health problems.' (Woman, 45-54 years, Castlemilk)

The majority of people in the general population saw the motive for the

Table 3 Significant impact on harassment by socio-demographic indicators

\begin{tabular}{|c|c|c|c|c|c|}
\hline & \multicolumn{2}{|c|}{$\begin{array}{l}\text { People with mental health problems } \\
\text { experiencing harassment }(n=67)\end{array}$} & \multicolumn{2}{|c|}{$\begin{array}{l}\text { General population experiencing } \\
\text { harassment }(n=24)\end{array}$} & \multirow{2}{*}{$\begin{array}{c}\text { Both samples } \\
\text { combined }\end{array}$} \\
\hline & $n(\%)$ & Statistics & $n(\%)$ & Statistics & \\
\hline \multicolumn{6}{|l|}{ Age (years) } \\
\hline $25-34$ & $9(33)$ & $P=0.033$ & $3(\mathrm{II})$ & $P=0.746$ & $P=0.038$ \\
\hline $35-44$ & $27(57)$ & $\chi^{2}=8.77$ & $9(19)$ & $\chi^{2}=1.23$ & $\chi^{2}=8.40$ \\
\hline $45-54$ & $14(48)$ & d.f. $=3$ & $6(13)$ & d.f. $=3$ & d.f. $=3$ \\
\hline $55-65$ & $17(40)$ & & $6(14)$ & NS & \\
\hline \multicolumn{6}{|c|}{ Frequency of leaving the home } \\
\hline Daily & $29(40)$ & $P=0.583$ & $7(19)$ & $P=0.353$ & $P=0.306$ \\
\hline Several times per week & $19(35)$ & $\chi^{2}=1.08$ & $6(22)$ & $\chi^{2}=2.08$ & $\chi^{2}=2.37$ \\
\hline \multirow[t]{2}{*}{ Weekly/monthly } & $14(47)$ & d.f. $=2$ & $5(38)$ & d.f. $=2$ & d.f. $=2$ \\
\hline & & NS & & & \\
\hline \multicolumn{6}{|l|}{ Owner of property } \\
\hline Local authority & $40(43)$ & $P=I .697$ & $18(30)$ & $P<0.001$ & $P=0.001$ \\
\hline Housing association & $12(40)$ & $\chi^{2}=0.64$ & 0 & $\chi^{2}=18.58$ & $\chi^{2}=17.70$ \\
\hline Privately owned & $14(39)$ & d.f. $=3$ & $5(7)$ & d.f. $=3$ & d.f. $=3$ \\
\hline Privately rented/other & I (I7) & NS & I (4) & & \\
\hline
\end{tabular}


Table 4 Features of the harassment $(n, \%)$

\begin{tabular}{cc}
\hline People with mental health \\
problems experiencing \\
harassment $(n=67)$
\end{tabular}$\quad \begin{gathered}\text { General population } \\
\text { experiencing } \\
\text { harassment }(n=24)\end{gathered}$

\section{Type of harassment}

\section{Verbal abuse}

Mental health problems exposed

Unwanted interference

Who committed the harassment

Teenagers

Neighbours

Family

Why the harassment occurred

Mental health problems

Vulnerability

Need/inadequacy of the harasser

To whom was the harassment reported?

Not reported

Police

Medical and social care staff

Effect of reporting the harassment

No difference

Intervention from other

Intervention from the police

Solutions attempted to stop the harassment

\section{None}

Moving house

Reasoning with the harasser

Was the harassment continuing?

Yes

No

Happens occasionally

Impact of the harassment

Adverse effect on mental health

Anger and annoyance

Fear

Most distressing aspect of the harassment

Adverse effect on mental health

Stigma of mental health problems

Anger and annoyance

What would stop or prevent harassment?

Education in schools and community

Change in public attitude

More effective policing

\begin{tabular}{|c|c|}
\hline $56(84)$ & $23(96)$ \\
\hline $36(54)$ & 0 \\
\hline $30(45)$ & $13(54)$ \\
\hline $25(37)$ & $18(75)$ \\
\hline $23(34)$ & $20(83)$ \\
\hline $14(2 \mathrm{I})$ & 0 \\
\hline $60(90)$ & 0 \\
\hline $29(43)$ & I (4) \\
\hline $28(42)$ & $13(54)$ \\
\hline $32(48)$ & $10(42)$ \\
\hline $29(43)$ & I7 (7I) \\
\hline $27(40)$ & 0 \\
\hline $30(45)$ & $16(67)$ \\
\hline I $8(27)$ & $5(2 I)$ \\
\hline II (I6) & $8(33)$ \\
\hline 31 (46) & $6(25)$ \\
\hline $20(30)$ & $3(13)$ \\
\hline II (I6) & $6(25)$ \\
\hline $30(45)$ & $10(42)$ \\
\hline $19(28)$ & $10(42)$ \\
\hline $9(13)$ & $2(8)$ \\
\hline $65(97)$ & $13(54)$ \\
\hline $34(5 I)$ & 21 (88) \\
\hline 3 I (46) & $12(50)$ \\
\hline $28(42)$ & $4(17)$ \\
\hline $27(40)$ & 0 \\
\hline $23(34)$ & $12(50)$ \\
\hline 31 (46) & $9(38)$ \\
\hline $25(37)$ & $5(2 I)$ \\
\hline $15(22)$ & $8(33)$ \\
\hline
\end{tabular}

I. For all participants $(n=330)$ : education in schools and community, II4 (37); change in public attitude, 89 (29); more effective policing, $63(2 \mathrm{l})$.

harassment as fulfilling a need of the harasser, such as to try to get money or, in the case of teenagers, looking for something to do:

'Children do it for sheer devilment, they want to annoy somebody.' (Woman [general population] 55-65 years, Drumchapel)
When the motive for the harassment was felt to be mental health problems, vulnerability or the person being different in some way, the most frequent feature of the harassment was verbal abuse, often in conjunction with exposing the mental health problems.

\section{Reporting the harassment}

For the purposes of this study the reporting of harassment was both formal, for example to the police, and informal, for example to medical or support staff. People with mental health problems were more reluctant to report harassment than were the general population. Nearly three-quarters of the general population $(n=17 / 24,71 \%)$ went to the police, compared with just under half of the people with mental health problems ( $n=29,43 \%)$.

There are several potential reasons why people with mental health problems may be reluctant to involve the police. There may be a fear that they will not be taken seriously and that the complaints they wish to make will be seen as a manifestation of their mental health problem. Because the police often can become involved with people with mental health problems under the Mental Health Act, individuals also may be wary of having voluntary contact, especially if they have had a negative experience in the past:

'The police have targeted me - I think they don't realise that I am ill. Last time I was admitted they had to come for me... I don't like the police, I try to tell them when I am high.' (Man, 55-65 years, Falkirk)

The majority of people reported the harassment to more than one agency and nearly half of the people with mental health problems also told medical or support staff about their problems:

'I reported it to my CPN [community psychiatric nurse] but there is nothing my CPN can do about it'. (Woman, 55-65 years, Drumchapel)

The majority of both groups found that reporting the harassment made no difference. This may make people reluctant to report further incidents to the police, which will have an impact on the monitoring of incidents that allows the police to target their services most effectively.

Although the general population reported the harassment more frequently, some had fears of repercussions if they involved the police:

'I was going to go to the police but I was worried it would cause more hassle.' (Woman [general population], 35-44 years, Drumchapel)

\section{Strategies to try to stop harassment}

Strategies included any action at all taken by the person other than reporting it. Over one-third ( $n=31,46 \%$ ) of the people with mental health problems took no action to 
attempt to stop the harassment. If they did take action it was the act of moving house; in fact, more people with mental health problems had moved house $(n=20,30 \%)$ than had tried to reason with the harasser $(n=11,16 \%)$ :

'I applied for a move to the housing off icer and got moved to where I live now where I am much happier and don't get any trouble.' (Man, 25-34 years, Glasgow)

\section{Continuing harassment}

Nearly half $(n=30 / 67,45 \%)$ of the people with mental health problems who had experienced harassment were still experiencing it at the time of interview. In the general population, the harassment was ongoing for a similar percentage of those who had experienced it $(n=10 / 24,42 \%)$.

Of the people with mental health problems experiencing continuing harassment, one-third ( $n=10 / 30,33 \%$ ) had reported it to the police and half additionally had reported it to medical professionals or support staff $(n=15 / 30,50 \%)$. Not surprisingly, the majority of these people felt that reporting had not made any difference. One-third of people had not reported the harassment at all.

\section{Impact of harassment}

Almost all the interviewees with mental health problems referred to the adverse effect that the harassment had had on their mental health. This was particularly the case when they felt that they were being harassed as a result of their mental health:

'I ended up in hospital virtually every month and my condition became worse.' (Woman, 35-44 years, Dumfries and Galloway)

Half of the general population sample in this study who experienced harassment spoke of a detrimental effect on their mental health.

'I became very stressed. My hair was falling out and I was very depressed.' (Woman [general population], 25-34 years, Aberdeen)

Overall, across the two samples, threequarters said that their mental health had been affected.

Anger and annoyance was described most frequently by the general population $(n=21 / 24,88 \%)$ and second most frequently described by people with mental health problems:

'I was very angry and wanted to put their heads through the wall, but that's no answer.' (Man, 55-65 years, Drumchapel)
One difference between the responses of the two samples to harassment was the level of fear in certain circumstances. If the harasser was not known to the individuals, a higher percentage of the general population talked of being annoyed than of the people with mental health problems, who more frequently described fear. Fear also was a common response when individuals felt that they were being harassed because of their mental health problems. Fear had resulted in people feeling the need to take actions to defend themselves from the perceived or actual threat:

'I actually sat in front of the TV one night with a rolling pin and a knife because I was worried they would get in and try and hurt me.' (Woman, 3544 years, Drumchapel)

A woman interviewee in Drumchapel described a situation where her neighbours were kicking her door to intimidate her. She had contacted the police and, while waiting for them to arrive, had picked up a knife. She describes how, understandably,

'The police misread the situation; even after I had put down the knife the attitude from the police was that I was the culprit, not my neighbour. (Woman, 45-54 years, Drumchapel)

\section{Preventing harassment}

All interviewees, regardless of whether they had experienced harassment or not, were asked what they felt would help to stop or prevent harassment. The responses were very similar across both groups. The most commonly cited response was 'education'. This was either education of the general public, with the aim of increasing knowledge and awareness of mental health problems, or education about the impact that antisocial behaviour can have on those who are its victims:

'Children should be educated so that they learn that people cannot help being different. The parents need to be educated as well so that they can stop the children behaving in this way. (Woman, 45-54 years, Drumchapel)

Intrinsically linked to education, and the second most common response, was a call for a positive change in public attitudes towards people with mental health problems.

\section{DISCUSSION}

\section{Overall prevalence of harassment}

This is the first study to compare the harassment of people with mental health problems with that of the general population. In total, people with mental health problems were more likely to experience harassment than the general population. This study is thus able to support the findings of Read \& Baker (1996), who described half of their respondents experiencing harassment; although the present study shows a lower overall prevalence, it achieved its sample in a more representative manner. Because there are a greater number of people in the general population sample who are in employment, they have more opportunity to experience workplace harassment. It seems that having mental health problems leaves people more vulnerable to experiencing harassment in their communities.

Only three people in this study came from ethnic minorities, therefore harassment of this group cannot be discussed. It is difficult to obtain figures for the likelihood of people experiencing harassment for other reasons such as race or gender, largely owing to the low level of reporting of 'low-level harassment' typified by verbal abuse. However, it is generally accepted that people from minority ethnic communities experience widespread racially motivated harassment (Social Exclusion Unit, 2002). Our study shows that having mental health problems can be treated also as a predictor of whether a person is likely to experience harassment.

The requirement by the Multi Centre Research Ethics Committee that community psychiatric nurses should approach patients may have led to a selective sample, possibly with a bias towards women and to people they felt would be more amenable to taking part or more likely to have experienced harassment. Likewise, because people from ethnic minorities are already known to use community mental health services less, community psychiatric nurses might have approached fewer of these people (Sainsbury Centre for Mental Health, 2002).

\section{Individual differences}

Similar amounts of harassment were reported by both genders in both samples. It might have been hypothesised that women experience more harassment than men, because of sexual harassment. This may be the case in the workplace but this study did not find an equivalent within the community. It is not known why age showed an influence on whether people had experienced harassment in the community. How frequently people left the house was significant to whether the 
general population sample and the two samples combined experienced harassment. It is felt that it did not prove to be significant for the sample of people with mental health problems because they experience harassment from within their own families without necessarily leaving their homes.

\section{Property and location}

Although there are many studies exploring public attitudes towards people with mental health problems in different types of neighbourhood (Brockington et al, 1993; Huxley, 1993; Wolff et al, 1996), they do not explore the actual behaviour of the community. The findings of this study show that it made little difference where people lived: people with mental health problems were more likely to have experienced harassment than the general population, wherever they lived. However, because the combined samples living in local authority accommodation were significantly more likely to experience harassment, this seems to indicate that there was a higher prevalence in lower socio-economic class areas (assuming property tenure as a proxy for socio-economic status), supporting the findings of Kelly \& McKenna (1997).

Living in supported accommodation has the potential either to draw attention to a person's mental health problems or to offer some protection through staff presence. People living in this accommodation were by no means entirely protected from harassment but it was slightly less prevalent than for people living in unsupported accommodation.

\section{Features of the harassment}

These findings show that for the $41 \%$ of people with mental health problems who had experienced harassment it had had a serious impact on their lives. As the majority of people with mental health problems are supported within the community, the experience there has the potential to profoundly affect their prognosis and overall quality of life. Mental health professionals need to be aware of these effects and be able to offer support and advice to their patients with confidence. Practitioners also must be proactive in raising the subject of patients' community experiences because patients may not recognise that this is a problem for which support can be provided.

\section{CLINICAL IMPLICATIONS}

Professionals should be aware that harassment is a problem for a significant number of people with mental health problems, regardless of the type of area in which they live. The community experience of patients, therefore, must be assessed regularly during consultation.

- The importance of anti-stigma initiatives at both a local and national level must be recognised.

- Professionals need to have knowledge of where to refer patients experiencing such difficulties for specific assistance and support within the context of multi-disciplinary and multi-agency working.

\section{LIMITATIONS}

It is impossible to assess objectively why a person becomes the target for harassment without having access to the perpetrator.

- By its very nature, the experience of harassment is subjective and people assume a causal relationship between harassment and deterioration in their mental health when other factors may have played a part.

There was possible selection bias and lack of ethnic minority representation.

KATHRYN M. BERZINS, MCC, ALISON PETCH, PhD, Nuffield Centre for Community Care Studies, University of Glasgow; JACQUELINE M. ATKINSON, PhD, Department of Public Health, University of Glasgow

Correspondence: Kathryn M. Berzins, Nuffield Centre for Community Care Studies, University of Glasgow, Gregory Building, 27 Lilybank Gardens, Glasgow GI2 8QQ, UK. Tel: 014I 330 5600; fax: 0141330 4976; e-mail: K.M.Berzins@clinmed.gla.ac.uk

(First received 9 August 2002, final revision II June 2003, accepted 19 June 2003)

There is an inherent difficulty in trying to identify why people were being harassed when only having access to the opinion of the victim. Participants were not asked why they felt they were harassed as a result of their mental health problems because this was felt to be too sensitive an area. This information therefore was acquired only if the participant volunteered it. It could be argued that the people with mental health problems were assuming that they were being harassed as a result of their mental health problems when this was not actually the case, or that they expected to be harassed because they recognised the stigma of their condition. Because almost half of the harassment that interviewees experienced, particularly verbal abuse, explicitly referred to their mental health problems, this counters the above suggestion.

The findings in this study are similar to those of Kelly \& McKenna (1997), with reports of children and teenagers committing what they termed 'low-level victimisation', including verbal abuse and attacks on property. They describe a similar scenario where people with mental health problems felt the need to arm themselves, potentially putting themselves at risk from prosecution.

There is little previous evidence looking at the impact that harassment can have on people with mental health problems. This study has shown, however, that harassment can affect the mental health of people without previous mental health problems.

The numbers of people moving house in this study had similarities to Read \& Baker's (1996) study, which found that $26 \%$ of people with mental health problems experiencing harassment moved house; this study showed a value of $30 \%$ (20/67). Because the results found no significant variations in harassment across different areas, this suggests that moving 
house is no guarantee that the harassment will not start again.

\section{Anti-stigma campaigns}

Because so much of this harassment is thought to occur as a result of negative public attitudes towards mental illness, continuing anti-stigma work must be given priority, such as that of the Royal College of Psychiatrists (2001) and the Department of Health (2001), as well as that carried out by devolved government and local initiatives.

With so much of the harassment committed by young people, this group in particular should be targeted in the most immediate campaigns in order to counter these negative attitudes.

\section{ACKNOWLEDGEMENTS}

We would like to acknowledge Harper Gilmour for assistance with statistical analysis.

\section{REFERENCES}

Brockington, I., Hall, P., Levings, J., et al (1993) The community's tolerance of the mentally ill. British Journal of Psychiatry, 162, 93-99.

Department of Health (200I) Mind Out for Mental Health (online): http: //www. mindout.net/

Hall, P., Brockington, I. F., Levings, J., et al (1993) A comparison of responses to the mentally ill in two communities. British Journal of Psychiatry, 162, 99-108.

Huxley, P. (1993) Location and stigma: a survey of community attitudes to mental illness. Journal of Mental Health, 2, 73-80.

Kelly, L. \& McKenna, H. (1997) Victimization of peopl with enduring mental illness in the community. Journal of Psychiatric and Mental Health Nursing, 3, 185-191.
Read, J. \& Baker, S. (1996) Not Just Sticks and Stones. London: MIND.

Royal College of Psychiatrists (200I) Changing Minds (online): http: //www.rcpsych.ac.uk/campaigns/cminds/ index.htm

Sainsbury Centre for Mental Health (2002) Breaking the Circles of Fear: a Review of the Relationship between Mental Health Services and African and Caribbean Communities. London: Sainsbury Centre for Mental Health.

Scottish Executive (1997) Scottish Framework for Mental Health Services. Edinburgh: Scottish Executive.

Social Exclusion Unit (2002) Minority Ethnic Issues in Social Exclusion and Neighbourhood Renewal. London: Social Exclusion Unit.

Wolff, G., Pathare, S., Craig, T., et al (1996) Community attitudes to mental illness. British journal of Psychiatry, 168, 183-190. 